\title{
Cryo-electron microscopy of an extremely halophilic microbe: technical aspects
}

\author{
Daniel Bollschweiler ${ }^{1,2} \cdot$ Miroslava Schaffer $^{1}$ C. Martin Lawrence ${ }^{1,3} \cdot$ \\ Harald Engelhardt ${ }^{1}$
}

Received: 23 November 2016 / Accepted: 19 December 2016 / Published online: 3 January 2017

(C) The Author(s) 2016. This article is published with open access at Springerlink.com

\begin{abstract}
Most halophilic Archaea of the class Halobacteriaceae depend on the presence of several molar sodium chloride for growth and cell integrity. This poses problems for structural studies, particularly for electron microscopy, where the high salt concentration results in diminished contrast. Since cryo-electron microscopy of intact cells provides new insights into the cellular and molecular organization under close-to-live conditions, we evaluated strategies and conditions to make halophilic microbes available for investigations in situ. Halobacterium salinarum, the test organism for this study, usually grows at $4.3 \mathrm{M} \mathrm{NaCl}$. Adaptation to lower concentrations and subsequent $\mathrm{NaCl}$ reduction via dialysis led to still vital cells at $3 \mathrm{M}$ salt. A comprehensive evaluation of vitrification parameters, thinning of frozen cells by focused-ion-beam micromachining, and cryo-electron microscopy revealed that structural studies under high salt conditions are possible in situ.
\end{abstract}

Communicated by A. Oren.

Electronic supplementary material The online version of this article (doi:10.1007/s00792-016-0912-0) contains supplementary material, which is available to authorized users.

Harald Engelhardt

engelhar@biochem.mpg.de

1 Max-Planck-Institut für Biochemie, Am Klopferspitz 18, 82152 Martinsried, Germany

2 Department of Biochemistry, University of Cambridge, Cambridge, UK

3 Department of Chemistry and Biochemistry, Montana State University, Bozeman, MT, USA
Keywords Halobacterium salinarum $\cdot$ Haloarchaea $\cdot$ Gas vesicles $\cdot$ Cryo-electron tomography $\cdot$ Focused-ion-beam micromachining $\cdot$ Vitrification

\section{Introduction}

Cryo-electron microscopy and cryo-electron tomography are successful techniques to investigate the structure and molecular organization of eukaryotic cells, intact bacteria, and archaea at close-to-live conditions (Baumeister 2015; Plitzko 2009). The availability of direct electron detectors and a new type of phase plate for transmission electron microscopes improve the resolution and visibility of structural details considerably (McMullan et al. 2014; Danev et al. 2014; Fukuda et al. 2015). These technical innovations further close the gap between molecular and cellular structure research as recent results of in situ cryo-electron tomography demonstrate (Khoshouei et al. 2016; Mahamid et al. 2016).

But there are still obstacles in the course of sample preparation for cryo-electron microscopy (cryo-EM) that may affect the native macromolecular organization or even the integrity of cells. Characteristic parameters of the organisms' natural or experimental environment, such as the temperature and composition of the growth medium, should ideally remain unchanged until vitrification. Although not frequently applied, moderate conditions are technically controllable during preparation, i.e. physiological temperatures around $37^{\circ} \mathrm{C}$ for microbial and mammalian cells, and common isoosmotic media for various organisms. However, temperatures around $100^{\circ} \mathrm{C}$ for hyperthermophilic archaea, or hypersaline media containing sodium chloride close to the saturation limit for extremely halophilic microbes are clearly detrimental or even inapplicable to 
sample preparation in cryo-EM. While thermophiles can be incubated at moderate temperatures prior to vitrification as a technical compromise, halophiles lyse in low salt conditions. Attempts to study extremely halophilic microorganisms by electron microscopy thus usually include cross-linking and chemical embedding (Robertson et al. 1982; Trachtenberg et al. 2000; Ring and Eichler 2001; Keklar et al. 2009; Pietilä et al. 2013) or air drying (Strunk et al. 2011; Fröls et al. 2012), an approach that was already applied in a very early study of Halobacterium (Houwink 1956).

In this study, we investigated approaches to make halophilic microbes available for in situ cryo-EM. Halobacterium salinarum is an extremely halophilic archaeon and grows in media containing $4.3 \mathrm{M} \mathrm{NaCl}$ (Oesterhelt and Krippahl 1983) which is far from common isoosmotic solutions supplemented with $\approx 0.14 \mathrm{M} \mathrm{NaCl}$ for (mostly mammalian) cells. Halobacterium salinarum thus constitutes a fastidious test organism. The strategy was to minimize the salt concentration without disturbing the vitality of the cells first and to find suitable conditions for vitrification and microscopy based on the required salinity of cell suspensions. We show that cryo-EM of halobacteria with salt concentrations up to $3 \mathrm{M} \mathrm{NaCl}$ is feasible.

\section{Materials and methods}

\section{Strains, media and growth}

Halobacterium salinarum strain S9 (Wagner et al. 1981) was originally obtained from the culture collection of the Department of Membrane Biochemistry (D. Oesterhelt), Max Planck Institute of Biochemistry, Martinsried, Germany. The growth medium consisted of $4.3 \mathrm{M} \mathrm{NaCl}$, $81 \mathrm{mM} \mathrm{MgSO}_{4}, 27 \mathrm{mM} \mathrm{KCl}, 10 \mathrm{mM} \mathrm{Na}$-citrate, and $1 \%$ w/v Oxoid peptone ( $\mathrm{pH} 7.1$ ). The inoculum was $10 \mathrm{ml}$ of freshly grown precultures $\left(48 \mathrm{~h}, \mathrm{OD}_{600} \approx 0.8\right)$ per 11 of medium for experimental purposes. Cells grew at $37^{\circ} \mathrm{C}$ while shaking at $100 \mathrm{rpm}$ in Erlenmeyer flasks and usually were collected in the late exponential growth phase after $72 \mathrm{~h}$ at an $\mathrm{OD}_{600}$ of $\approx 0.9$.

Swarm agar plates consisted of normal medium and $0.3 \% \mathrm{w} / \mathrm{v}$ agar. The inoculum $(10 \mu \mathrm{l}$ of late growth phase cultures) was placed in the center of the plates and incubated for 5 days at $37^{\circ} \mathrm{C}$. Cells were picked from the edge of the most motile culture out of 5 parallel experiments, inoculated into $50 \mathrm{ml}$ of liquid medium and incubated as usual, inspected for motility in the microscope and used for further selection of motile cells on swarm agar plates. Halobacterium salinarum showed a significantly increased swarm motility after 5 cycles (strain S9 SW\#5; Online
Resource 1) that was indistinguishable concerning motility from samples after 10 cycles.

\section{Dialysis approach}

Aliquots $(12 \mathrm{ml})$ of $H$. salinarum cultures, grown for 60 to $72 \mathrm{~h}\left(\mathrm{OD}_{600} 0.9\right.$ to 1.0$)$, were dialyzed in Slide-A-Lyzer ${ }^{\mathrm{TM}}$ bags against a gently stirred solution of $81 \mathrm{mM} \mathrm{MgSO}_{4}$ (1 l) at room temperature (RT). Samples of $0.2 \mathrm{ml}$ taken from the cell suspensions during the dialysis experiments were analyzed for the remaining salt and inspected for the integrity of cells by microscopy. The dialysis kinetics had been characterized beforehand. For this a $4.3 \mathrm{M} \mathrm{NaCl}$ plus $81 \mathrm{mM} \mathrm{MgSO}_{4}$ solution was dialyzed as above and the residual salt analyzed every $7 \mathrm{~min}$. The osmometer OSMOMAT $^{\text {TM }} 030$ (Gonotec, Berlin, Germany) served to determine the osmolality of samples. The measures were calibrated by means of reference solutions containing $81 \mathrm{mM}$ $\mathrm{MgSO}_{4}$ and 0 to $4.3 \mathrm{M} \mathrm{NaCl}$ to calculate the concentration of $\mathrm{NaCl}$.

Halobacterium salinarum intended for growth at lower salt concentrations were collected from cultures containing $4.3 \mathrm{M} \mathrm{NaCl}$, dialyzed as described above against 11 of medium with the reduced salt content for $2 \mathrm{~h}$ and used as inoculum for cultures with corresponding $\mathrm{NaCl}$ concentrations. Cell suspensions for cryo-electron microscopy experiments were dialyzed accordingly against a standard solution of $3 \mathrm{M} \mathrm{NaCl}$ plus $81 \mathrm{mM} \mathrm{MgSO}_{4}$ at RT or $37^{\circ} \mathrm{C}$.

\section{Vitrification and cryo-electron microscopy}

Halobacterium salinarum cells $(1 \mathrm{ml})$ were centrifuged at $150 \times \mathrm{g}$ for $30 \mathrm{~min}$, the supernatant carefully removed and the concentrated cell suspension mixed with $0.1 \mathrm{ml}$ of standard salt solution. $100 \mu \mathrm{l}$ of colloidal $10 \mathrm{~nm}$-sized BSA-coated gold markers (Aurion) were spun down using a benchtop centrifuge $(4000 \times g, 10 \mathrm{~min})$. The supernatant was discarded and the gold marker pellet resuspended in $100 \mu \mathrm{l} 3 \mathrm{M} \mathrm{NaCl}$ standard salt solution. $4 \mu \mathrm{l}$ of this gold marker resuspension and $4 \mu \mathrm{l}$ of the cell suspension were applied to Quantifoil ${ }^{\mathrm{TM}} \mathrm{Cu} 200 \mathrm{R} 2 / 1$ grids that had been exposed to glow discharge for $30 \mathrm{~s}$. After blotting, the samples were plunge-frozen using a home-made plunger (Plitzko and Baumeister 2007) or a Vitrobot ${ }^{\mathrm{TM}}$ Mark IV (FEI, Eindhoven, The Netherlands) at RT and inspected in a Tecnai Polara G2 transmission electron microscope (FEI), equipped with a $300 \mathrm{kV}$ field emission gun, a postcolumn energy filter, and a $2 k \times 2 k$ CCD detector (GATAN Inc., Pleasanton, California, USA). Data were recorded under cryo-conditions (about $-190{ }^{\circ} \mathrm{C}$ ) and low-dose exposure (60-120 $\mathrm{e}^{-} / \AA^{2}$ total dose) at primary magnifications of $18,000 \times$ or $22,500 \times$. 
Focused-ion-beam (FIB) milling for thinning of vitrified samples on grids prior to cryo-EM was performed in a Quanta ${ }^{\mathrm{TM}}$ 3D FEG dual beam FIB scanning electron microscope (SEM; FEI, Eindhoven, The Netherlands) under cryo-conditions. Milling was performed by cutting wedges of 15 to $20 \mu \mathrm{m}$ width into the specimen at an angle of $4^{\circ}-6^{\circ}$, as described in more detail in (Rigort et al. 2010; Rigort and Plitzko 2015; Schaffer et al. 2016). Accompanying SEM images were recorded at $3 \mathrm{kV}$ acceleration voltage and a beam current of $20 \mathrm{pA}$ at $10,000 \times$ magnification for preparation control.

\section{Results and discussion}

High amounts of salt in cell suspensions diminish contrast between the structures of microbial cells and the surrounding medium in cryo-EM. Furthermore, $\mathrm{NaCl}$ at concentrations close to the saturation limit is prone to crystallize swiftly, evaporation considerably changes the concentration in small droplets on grids for electron microscopical investigations, and the increased viscosity of the solution has effects on the blotting behavior during sample preparation. These features require carefully adapted vitrification parameters for cryo-EM. To accomplish reasonable starting conditions and to avoid unnecessarily high salt concentrations for electron microscopy, we first attempted to minimize the salinity of media to a point where viability and vitality of $H$. salinarum were not yet impaired.

\section{Minimal salt conditions for $\boldsymbol{H}$. salinarum}

We chose two criteria to identify healthy and viable cells: growth and motility. To increase the relative amount of motile cells, $H$. salinarum strain $\mathrm{S} 9$ was grown on swarm agar plates and repeatedly selected for particularly motile populations as described in Materials and Methods. The resulting test strain contained $80-90 \%$ actively moving cells at the end of the exponential growth phase (72 h) when inspected in the light microscope. These microbes showed massive flagellation (see Online Resource 1). Shorter $(50 \mathrm{~h})$ or longer $(90 \mathrm{~h})$ growth was unfavorable since cells were less motile or progressively lysed, respectively.

We cultivated strain SW\#5 in media with original and reduced $\mathrm{NaCl}$ content to evaluate the lower limit of the cells' salt tolerance. The $\mathrm{Mg}^{2+}$ concentration remained unchanged since $H$. salinarum needs divalent ions for the integrity of its S-layer, which functions as the stable cell wall (Engelhardt 2007, 2016). The strain showed apparently unimpaired growth down to $3 \mathrm{M} \mathrm{NaCl}$ but only minimal growth at $2.5 \mathrm{M}$. This result is in agreement with other observations (Zeng et al. 2006). However, only $H$. salinarum in $3.5 \mathrm{M} \mathrm{NaCl}$ medium was indistinguishable from cells in control samples $(4.3 \mathrm{M})$. Halobacterium salinarum cultivated with $3.0 \mathrm{M}(2.5 \mathrm{M})$ $\mathrm{NaCl}$ showed $\leq 10 \%(\geq 80 \%)$ aberrant and $\geq 70 \%(>90 \%)$ immotile cells. Investigations by Vauclare et al. (2015) revealed that the intracellular $\mathrm{KCl}$ content dropped concomitantly with external salt concentrations $\leq 2.5 \mathrm{M}-H$. salinarum adapts the osmotic pressure by accumulating $\mathrm{KCl}$ in the cytoplasm (Oren 2008) — and that the integrity of cytosolic proteins suffered from low salt conditions. According to our results, growth media contained $3.5 \mathrm{M}$ $\mathrm{NaCl}$ for subsequent experiments.

The approach for further salt reduction was to remove $\mathrm{NaCl}$ by dialysis after cell growth. Figure 1 illustrates that the amount of intact cells decreased below $2.5 \mathrm{M}$ but remained almost unchanged to $3.0 \mathrm{M} \mathrm{NaCl}$. The cells were still fully motile and did not show other obvious shortcomings compared to the control without salt reduction. The basic amount of lysed cells ( $\approx 10 \%$ on average) appears to originate from the long-term culture and may also include false positives. Short-time exposure to lower salinity is indeed less harmful to $H$. salinarum than incubation for many hours or several days (Vauclare et al. 2015). We, therefore, combined cell growth at $3.5 \mathrm{M}$ $\mathrm{NaCl}(72 \mathrm{~h})$ and short-term dialysis to $3.0 \mathrm{M} \mathrm{NaCl}$ at constant $81 \mathrm{mM} \mathrm{MgSO}_{4}$ prior to vitrification experiments (total time after dialysis until freezing less than $1 \mathrm{~h}$ ).

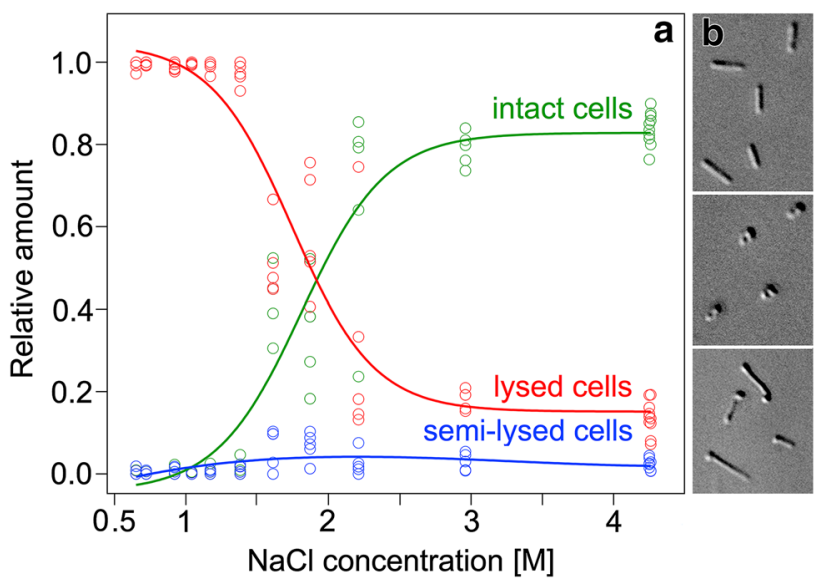

Fig. 1 Morphological integrity of Halobacterium salinarum in $\mathrm{NaCl}$ solutions. Cells were grown in $4.3 \mathrm{M} \mathrm{NaCl}$ and $81 \mathrm{mM} \mathrm{MgSO}_{4}$ and dialyzed against a solution of $81 \mathrm{mM} \mathrm{MgSO}_{4}$. a Plot of the relative amount of intact, lysed, and semi-lysed cells with respect to the remaining $\mathrm{NaCl}$ concentration after dialysis. Analysis of 60 microscopic frames containing 8139 cells in total. Curve fits were calculated using Igor Pro 6.3 (WaveMetrics ${ }^{\circledR}$ ). b Selected cells illustrating intact, lysed, and semi-lysed states (from top to bottom) in the light microscope (DIC imaging) 


\section{Plunge freezing of $\mathrm{H}$. salinarum in $3 \mathrm{M} \mathrm{NaCl}$}

In a first series of experiments, we vitrified $H$. salinarum for cryo-EM by means of a commonly used manual plunger without atmospheric control (Plitzko and Baumeister 2007) taking additional care of the temperature of the cell suspension prior to plunging (for parameters and observations see Online Resource 2). Keeping cells at cultivation temperature $\left(37^{\circ} \mathrm{C}\right)$ instead of room temperature (RT) had no detectable improving effect on the sample quality after vitrification and was thus suspended in further tests. Blotting of grids from the sample side (grid side where the cell suspension was applied) led to cell loss while blotting from the back side turned out to be advantageous. This prevented direct contact of cells with the blotting paper while draining excess liquid through the holey carbon foil. The blotting time was critical; about $3 \mathrm{~s}$ gave best results whereas $\approx 1 \mathrm{~s}$ led to a very thick ice layer and $\approx 10 \mathrm{~s}$ to damage of the carbon film (for detailed results see Online Resource 2). However, the ice thickness was always highly variable and sample quality was difficult to reproduce; the conditions and procedure of the manual approach could not be sufficiently standardized. We, therefore, switched to a commercial plunger (Vitrobot ${ }^{\mathrm{TM}}$ Mark IV) and adapted the following device-controlled parameters in a series of experiments: humidity, blotting strength and time (for detailed results see Online Resource 3). Working at room temperature and $100 \%$ humidity in the sample chamber and the ability to blot from both sides provided some additional flexibility that allowed further optimization of the blotting protocol. While a $3 \mathrm{~s}$ blotting time always produced a thick or very thick ice layer (if combined with a low blotting strength), blotting for $7 \mathrm{~s}$ or longer resulted in thin or very thin ice. The best settings with an acceptable but still variable distribution of cells on the grid were a blotting time of $5 \mathrm{~s}$ at medium blotting strength (Online Resource 3). Cell lysis was minimal under these conditions and we only occasionally observed gas vesicles outside of microbes, indicating rupture of only a few cells in the course of the preparation process (Fig. 2).

\section{Vitrified $\boldsymbol{H}$. salinarum cells in cryo-electron microscopy}

Most $H$. salinarum cells were between 0.5 and $0.7 \mu \mathrm{m}$ in thickness (Fig. 2) and thus in a range that would still permit data collection for cryo-electron tomography. But the high $\mathrm{KCl}$ concentration inside the cytoplasm leads to considerable cellular contrast and tends to obliterate the contributions of biological structures. Cells that had lost part of their cytoplasm by limited lysis in $2.5 \mathrm{M} \mathrm{NaCl}$ occurred flattened in the microscope and showed remaining cellular details, e.g. the putative polar cap structure (Kupper et al. 1994; Metlina 2004), with reasonable contrast (Online

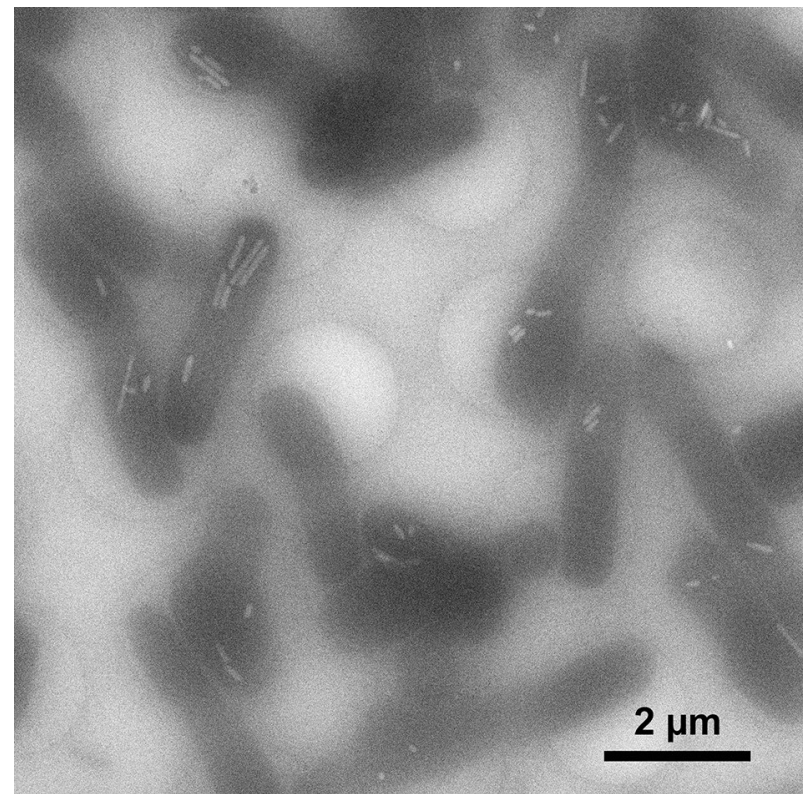

Fig. 2 Cryo-electron microscopy of intact Halobacterium salinarum cells after vitrification in $3 \mathrm{M} \mathrm{NaCl}$ plus $81 \mathrm{mM} \mathrm{MgSO}_{4}$. Cells were grown for $72 \mathrm{~h}\left(\mathrm{OD}_{600} 0.9\right)$. Bright cell inclusions are gas vesicles. The single small gas vesicle in the "empty" carbon hole (top right) of the grid originates from a lysed cell. The low signal-to-noise ratio of the image is due to the limited electron dose $\left(\approx 60 \mathrm{e}^{-} / \AA^{2}\right)$, the thickness of the ice layer $(>500 \mathrm{~nm})$ and the contrast contribution of the salt

Resource 4). We, therefore, applied cryo-FIB milling to thin intact frozen-hydrated samples in a controlled manner. Halobacteria are too small to be addressed by selective thinning as is possible and necessary for larger cells (Rigort et al. 2010; Schaffer et al. 2016). We cut wedges into the specimen covering 5-6 holes of the grid, so that cells located in these holes became concomitantly thinned (Fig. 3). The yield of individual microbes suitable for appropriate structural analysis largely depended on the distribution and orientation of cells and was difficult to predict prior to inspection in the transmission electron microscope. Importantly, while we found that cryo-FIB treatment of $H$. salinarum and cryo-EM in $3 \mathrm{M} \mathrm{NaCl}$ is technically practical, it is advisable to prepare a number of FIB milled EM grids to obtain a series of suitable data.

\section{Conclusions}

The conjecture that cellular cryo-electron microscopy of extreme halophiles is impossible because of the exceptionally high salt requirement for cell integrity apparently excluded an interesting group of microbes from in-situ investigations. In this study, we showed that halophilic microbes can be imaged under close-to-live 


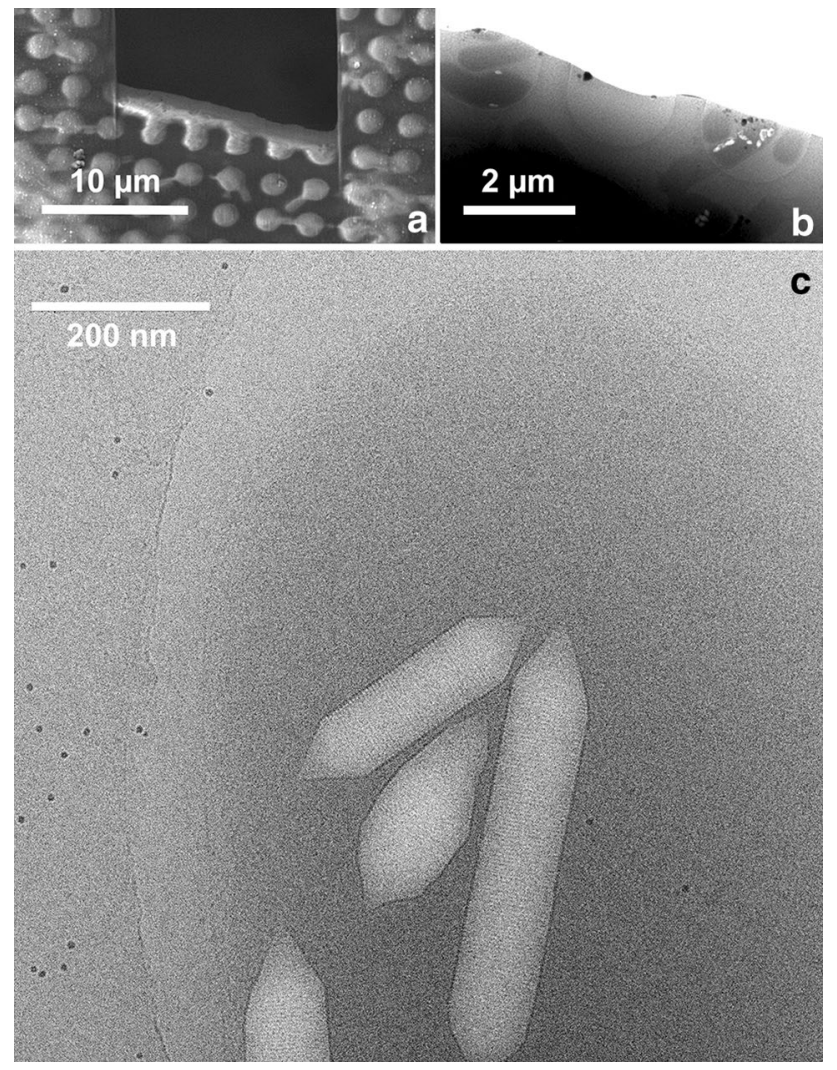

Fig. 3 Thinning of a vitrified sample from Halobacterium salinarum in $3 \mathrm{M} \mathrm{NaCl}$ plus $81 \mathrm{mM} \mathrm{MgSO}$ by FIB micromachining. a Scanning electron micrograph of a grid region showing a wedge-like cutout. The ice layer in grid holes (bright) at the cutting edge is partly thinned. b Cryo-transmission electron micrograph of three grid holes, two of them containing thinned cells. c Image of a thinned $\mathrm{H}$. salinarum cell containing gas vesicles. The periodicity of the vesicle "ribs" $(4.6 \mathrm{~nm})$ is clearly visible. The contrast of the cell membrane and S-layer is low due to the limited electron dose and the moderate defocus. The closest lateral distance of the individual gas vesicles to the estimated location of the cell membrane is between $\approx 15$ and $240 \mathrm{~nm}$

conditions. The crucial technical step is the adaptation of the vitrification process that turned out to be delicate and critical for obtaining healthy cells for visualization. The still remaining variability of the cell distribution and ice thickness likely is a principal problem of the badly defined blotting process (Glaeser et al. 2016). Very recently developed "self-blotting" grids may possibly help to improve the situation in the future (Razinkov et al. 2016). Nevertheless, the parameter settings evaluated here serve as a guideline for the preparation of halophiles in general. While vitrified cells have not been investigated in solutions clearly beyond 0.1 to $0.2 \mathrm{M}$ salt so far, with one exception (Zenke et al. 2015), there are already a few studies on isolated viruses from halophilic microbes in 1-1.3 M NaCl (Jäälinoja et al. 2008; Aalto et al. 2012; Pietilä et al. 2013). These experiments and our own experiences suggest that cryo-EM of halophiles in media below $\approx 2 \mathrm{M}$ salt is not exceedingly problematic; beyond that, in-situ investigations become increasingly challenging.

Salt concentrations as high as $3 \mathrm{M} \mathrm{NaCl}$ are manageable but are not ideal for routine and high throughput approaches. Gentle adaptation of cells to less salt via growth and subsequent dialysis was necessary for $H$. salinarum and might also be a promising strategy to establish convenient conditions for microscopical preparation and imaging for species with more moderate salt requirements. Halobacterium salinarum and other haloarchaea need divalent anions to protect the cell wall (here the S-layer) against osmotic pressure differences (Engelhardt 2007; Kessel et al. 1988). The $\mathrm{Mg}^{2+}$ concentration thus should be sufficiently high in corresponding experiments. But divalent anions also appear to play a role for the functional integrity of peptidoglycan in (halophilic) bacteria (Mouné et al. 2000; Kern et al. 2010).

The salinity of the external medium is not the only parameter that matters for cryo-EM. Cells accumulate salt $(\mathrm{KCl})$ and/or compatible solutes such as amino acids, derivatives thereof, or other compounds to compensate osmotic effects of the saline environment (Jehlička and Oren 2013). Particularly, internal $\mathrm{KCl}$ in considerable amounts increases the mass density such that the contrast of biological material becomes compromised in the electron microscope. If microbes follow the high-salt-in strategy, e.g. Halobacteriaceae, Halanaerobiales and Salinibacter ruber (Oren 2008), reducing the internal concentration by growth adaptation and complementary short-term dialysis is advantageous or even indispensable for imaging intracellular structures. By this way and combined with thinning of intact cells by FIB milling, the characterization of individual halobacterial organelles in situ such as the flagellar motor together with its polar cap (Kupper et al. 1994; Metlina 2004) or the cellular morphogenesis of gas vesicles (Pfeifer 2012) should be approachable now.

Acknowledgements Open access funding provided by Max Planck Society. We thank our colleagues Jürgen M. Plitzko for valuable advice with cryo-electron microscopy, Jan Lubieniecki and Paul Weyh for skilfull technical assistance. We also thank Dieter Oesterhelt for a stock culture of $H$. salinarum S9. The project was supported by a Grant of the Deutsche Forschungsgemeinschaft (EN 144/4-1).

Open Access This article is distributed under the terms of the Creative Commons Attribution 4.0 International License (http:// creativecommons.org/licenses/by/4.0/), which permits unrestricted use, distribution, and reproduction in any medium, provided you give appropriate credit to the original author(s) and the source, provide a link to the Creative Commons license, and indicate if changes were made. 


\section{References}

Aalto AP, Bitto D, Ravantti JJ, Bamford DH, Huiskonen JT, Oksanen HM (2012) Snaphot of virus evolution in hypersaline environments from the characterization of a membrane-containing Salisaeta icosahedral phage 1. Proc Natl Acad Sci USA 109:7079-7084

Baumeister W (2015) Electron cryomicroscopy: from molecules to cells. J Phys Conf Ser. doi:10.1088/1742-6596/522/1/012003

Danev R, Buijsse B, Khoshouei M, Plitzko JM, Baumeister W (2014) Volta potential phase plate for in-focus phase contrast transmission electron microscopy. Proc Natl Acad Sci USA 111:15635-15640

Engelhardt H (2007) Mechanism of osmoprotection by archaeal S-layers: a theoretical study. J Struct Res 160:190-199

Engelhardt H (2016) S-layers. In: Encyclopedia of life sciences. Wiley, Chichester. doi:10.1002/9780470015902.a0021936

Fröls S, Dyall-Smith M, Pfeifer F (2012) Biofilm formation by haloarchaea. Environ Microbiol 14:3159-3174

Fukuda Y, Laugks U, Lucic V, Baumeister W, Danev R (2015) Electron cryotomography of vitrified cells with a Volta phase plate. $\mathrm{J}$ Struct Biol 190:143-154

Glaeser R, Han B-G, Csencsits R, Killilea A, Pulk A, Cate JHD (2016) Factors that influence the formation and stability of thin, cryo-EM specimens. Biophys J 110:749-755

Houwink AL (1956) Flagella, gas vacuoles and cell-wall structure in Halobacterium halobium; an electron microscope study. J Gen Microbiol 15:146-150

Jäälinoja HAT, Roine E, Laurinmäki P, Kivelä HM, Bamford DH, Butcher SJ (2008) Structure and host-cell interaction of SH1, a membrane-containing, halophilic euryarchaeal virus. Proc Natl Acad Sci USA 105:8008-8013

Jehlička J, Oren A (2013) Raman spectroscopy in halophile research. Front Microbiol. doi:10.3389/fmicb.2013.00380

Keklar J, Hammerlund K, Robinson CK, DiRuggiero J, Roberts KP (2009) Electron microscopy studies of desiccated halobacterium. Abstr Pap Am Chem Soc 237:336

Kern T, Giffard M, Hediger S, Amoroso A, Giustini C, Bui NK, Joris B, Bougault C, Vollmer W, Simorre JP (2010) Dynamics characterization of fully hydrated bacterial cell walls by solid-state NMR: Evidence for cooperative binding of metal ions. J Am Chem Soc 132:10911-10919

Kessel M, Wildhaber I, Cohen S, Baumeister W (1988) Three-dimensional structure of the regular surface glycoprotein layer of Halobacterium volcanii from the Dead Sea. EMBO J 7:1549-1554

Khoshouei M, Radjainia M, Phillips AJ, Gerrard JA, Mitra AK, Plitzko JM, Baumeister W, Danev R (2016) Volta phase plate cryo-EM of the small protein complex Prx3. Nat Commun 7:10534. doi:10.1038/ncomms 10534

Kupper J, Marwan W, Typke D, Grünberg H, Uwer U, Gluch M, Oesterhelt D (1994) The flagellar bundle of Halobacterium salinarium is inserted into a distinct polar cap structure. $\mathrm{J}$ Bacteriol 176:5184-5187

Mahamid J, Pfeffer S, Schaffer M, Villa E, Danev R, Kuhn Cuellar L, Förster F, Hyman AA, Plitzko JM, Baumeister W (2016) Visualizing the molecular sociology at the HeLa cell nuclear periphery. Science 351:969-972

McMullan G, Faruqi AR, Clare D, Henderson R (2014) Comparison of optimal performance at $300 \mathrm{keV}$ of three direct electron detectors for use in low dose electron microscopy. Ultramicroscopy 147:156-163

Metlina AL (2004) Bacterial and archaeal flagella as prokaryotic motility organelles. Biochem (Moscow) 69:1203-1212

Mouné S, Eatock C, Matheron R, Willison JC, Hirschler A, Herbert R, Caumette P (2000) Orenia salinaria sp. nov., a fermentative bacterium isolated from anaerobic sediments of Mediterranean salterns. Intl J Sys Evol Microbiol 50:721-729

Oesterhelt D, Krippahl G (1983) Phototrophic growth of halobacteria and its use for isolation of photosynthetically-deficient mutants. Ann Microbiol (Paris) 134B:137-150

Oren A (2008) Microbial life at high salt concentrations: phylogenetic and metabolic diversity. Saline Syst. doi:10.1186/1746-1448-4-2

Pfeifer F (2012) Distribution, formation and regulation of gas vesicles. Nat Rev Microbiol 10:705-715

Pietilä MK, Larinmäki P, Russell DA, Ko C-C, Jacobs-Sera D, Butcher SJ, Bamford DH, Hendrix RW (2013) Insights into head-tailed virus infecting extremely halophilic archaea. J Virol 87:3248-3260

Plitzko JM (2009) Cellular cryo-electron tomography (CET): Towards a voyage to the inner space of cells. In: Anselmetti D (ed) Single cell analysis: technologies and applications. Wiley-VCH, Weinheim, pp 39-68

Plitzko JM, Baumeister W (2007) Cryoelectron tomography (CET). In: Hawkes PW, Spence JH (eds) Science of microscopy, vol I. Springer, New York, pp 535-604

Razinkov I, Dandey VP, Wei H, Zhang Z, Melnekoff D, Rice WJ, Wigge C, Potter CS, Carragher B (2016) A new method for vitrifying samples for cryoEM. J Struct Biol 195:190-198

Rigort A, Plitzko JM (2015) Cryo-focused-ion-beam applications in structural biology. Arch Biochem Biophys 581:122-130

Rigort A, Bäuerlein FJB, Leis A, Gruska M, Hoffmann C, Laugks T, Böhm U, Eibauer M, Gnaegi H, Baumeister W, Plitzko JM (2010) Micromachining tools and correlative approaches for cellular cryo-electron tomography. J Struct Biol 172:169-179

Ring G, Eichler J (2001) characterization of inverted membrane vesicles from the halophilic archaeon Haloferax volcanii. J Membrane Biol 183:195-204

Robertson JD, Schreil W, Reedy M (1982) Halobacterium halobium I. A thin-sectioning electron microscopic study. J Ultrastruct Res $80: 148-162$

Schaffer M, Mahamid J, Engel BD, Laugks T, Baumeister W, Plitzko JM (2016) Optimized cryo-focused ion beam sample preparation aimed at in situ structural studies of membrane proteins. J Struct Biol. doi:10.1016/j.jsb.2016.07.010

Strunk T, Hamacher K, Hoffgaard F, Engelhardt H, Zillig MD, Faist K, Wenzel W, Pfeifer F (2011) Structural model of the gas vesicle protein GvpA and analysis of GvpA mutants in vivo. Mol Microbiol 81:56-68

Trachtenberg S, Pinnick B, Kessel M (2000) The cell surface glycoprotein layer of the extreme halophile Halobacterium salinarum and its relation to Haloferax volcanii: Cryo-electron tomography of freeze-substituted cells an projection studies of negatively stained envelopes. J Struct Biol 130:10-26

Vauclare P, Mary V, Fabiani E, Martinez N, Jasnin M, Gabel F, Peters J, Zaccai G, Frenzetti B (2015) Molecular adaptation and salt stress response of Halobacterium salinarum cells revealed by neutron spectroscopy. Extremophiles 19:1099-1107

Wagner G, Oesterhelt D, Krippahl G, Lanyi JK (1981) Bioenergetic role of halorhodopsin in Halobacterium halobium cells. FEBS Lett 131:341-345

Zeng C, Zhu J-C, Liu Y, Yang Y, Zhu J-Y, Huang Y-P, Shen P (2006) Investigation of the influence of $\mathrm{NaCl}$ concentraion on Halobacterium salinarum growth. J Therm Analysis Calometry 84:625-630

Zenke R, von Gronau S, Bolhuis H, Gruska M, Pfeiffer F, Oesterhelt D (2015) Fluorescence microscopy visualization of halomucin, a secreted $927 \mathrm{kDa}$ protein surrounding Haloquadratum walsbyi cells. Front Microbiol 6: 249, doi:10.3389/fmicb.2015.00249 